\title{
Iatrogenic bladder injuries during obstetric and gynecological surgeries-does it demand prophylactic presence of an urologist?
}

\author{
Sankareswari R. ${ }^{1 *}$, Ghurunaath T. R. ${ }^{2}$, Ramya Sreevarshni Shunmugha Sundharam ${ }^{1}$
}

\begin{abstract}
${ }^{1}$ Department of Obstetrics and Gynaecology, ${ }^{2}$ Department of Urology, Sri Venkateshwaraa Medical College Hospital and Research centre, Ariyur, Pondicherry, India.
\end{abstract}

Received: 11 February 2017

Revised: 04 March 2017

Accepted: 06 March 2017

\author{
*Correspondence: \\ Dr. Sankareswari R, \\ E-mail: mlrsreekrishna@gmail.com
}

Copyright: $\odot$ the author(s), publisher and licensee Medip Academy. This is an open-access article distributed under the terms of the Creative Commons Attribution Non-Commercial License, which permits unrestricted non-commercial use, distribution, and reproduction in any medium, provided the original work is properly cited.

\begin{abstract}
Background: Iatrogenic bladder injuries (IBI) are more common during obstetric and gynaecological procedures averaging 2.6 IBIs per 1000 surgeries. The objective of the study was to estimate the incidence of IBIs during OBG procedures in a tertiary care hospital at Puducherry. To study the proportion and clinical profile of the IBIs where the management of an urologist was indicated intra-operatively.

Methods: This cross-sectional study was conducted in a tertiary care hospital in Puducherry by analysis of records of OBG surgeries conducted during the 5 years' period from 2011 to 2015. The occurrence of IBIs during obstetric and gynaecological surgeries was estimated and the records of those with injuries were analysed retrospectively.

Results: The overall incidence of Iatrogenic Bladder Injuries (IBI) among the OBG surgeries was $1.33 \%(\mathrm{n}=19)$. Iatrogenic Bladder Injuries (IBI) frequently happened during Gynaecological procedures $(73.7 \%, n=14)$ than during Obstetric procedures $(26.3 \%, \mathrm{n}=5)$. The incidence of bladder injuries intra-operatively was more frequent during dissection of bladder $(57.9 \%, \mathrm{n}=11)$ and opening the abdomen $(36.8 \%, \mathrm{n}=7)$. The requirement of urologist was more felt during posterior bladder wall injuries $(26.3 \%, \mathrm{n}=5)$.

Conclusions: The occurrence of IBIs was more common during Gynaecological procedures than during obstetric procedures. Most of the gynaecological procedures especially hysterectomies require the expertise presence of an urologist.
\end{abstract}

Keywords: Gynaecological procedures, Iatrogenic bladder injuries, Obstetric procedures

\section{INTRODUCTION}

No matter what measures are taken, doctors will sometimes falter, and it isn't reasonable to ask that we achieve perfection. What is reasonable is to ask that we never cease to aim for It. Says Atul Gawande, a surgeon, writer, and public health researcher. Embryologically the urinary system and genital system have a common origin. Hence as anatomically they are in close proximities so is surgically the incidence of injuries to the urinary tract whenever there is any surgery done involving the genital tract. Iatrogenic bladder injuries (IBI) are more common during obstetric and gynaecological procedures averaging 2.6 IBIs per 1000 surgeries. ${ }^{1,2}$ The injuries to the urinary tract call for an urologist management intra-operatively most of the times to avoid sequelae. This paper aims at observing the incidence of IBIs during OBG procedures in a tertiary care hospital and if the management of the 
same required an urologist intra-operatively. This gives a scope on knowing the prophylactic requirement of the presence of an urologist during OBG procedures.

\section{METHODS}

This cross-sectional study was conducted in a tertiary care hospital in Puducherry by analysis of records of OBG surgeries conducted and the cases referred to urology department during the 5 years period from 2011 to 2015. Iatrogenic bladder injuries (IBI) were defined as injuries which occurred unintentionally during or after OBG procedures which needed unplanned repair6. The occurrence of IBIs during obstetric and gynaecological surgeries was estimated and the records of those with injuries were analysed retrospectively in terms of site and characteristics of injury, difference in management by different specialists, requirement of urologist for management, type of suturing, need for cystoscopy and catheter in situ placement. All the cases were followed up till discharge to ensure any complications post-surgery. Those cases which were managed by the urologist required an on-table intra-operative urgency to call the urologist for expertise management of IBIs.

\section{Statistical analysis}

Data entry was done in Microsoft Excel 2010 and secondary data analysis was done in SPSS version18. Data is represented as frequencies and percentages. Chi square test was used to find significant differences between two categorical variables and Chi square for trends test was used to compute significant differences within sub-group variables of two categories keeping a reference sub-group. Mann Whitney $U$ test was used to find significant difference between two means whose array followed a non-parametric distribution (analysed with Kolmogorov-Smirnov test).

\section{RESULTS}

A total of 1427 surgeries were conducted by the department of Obstetrics and Gynaecology during the period of 5 years from 2011-2015 which included gynaecological procedures like hysterectomies $(n=753$, $52.8 \%$ ), obstetric procedures like Lower segment caesarean section (LSCS) $(\mathrm{n}=599,42 \%)$ and puerperal sterilizations $[\mathrm{PS}] \mathrm{z}(\mathrm{n}=75,5.2 \%)$. The overall incidence of Iatrogenic Bladder Injuries (IBI) among the OBG surgeries was $1.33 \%(n=19)$. The mean age group of the study participants was $42 \pm 11.35$ years. Majority $(94.5 \%$, $\mathrm{n}=18$ ) among them were multiparous women. Iatrogenic Bladder Injuries frequently happened during Gynaecological procedures $(73.7 \%, \mathrm{n}=14)$ than during Obstetric procedures $(26.3 \%, \mathrm{n}=5)$. The incidence of bladder injuries intra-operatively was more frequent during dissection of bladder $(57.9 \%, \mathrm{n}=11)$ and opening the abdomen $(36.8 \%, \mathrm{n}=7)$. IBI recognized postoperatively as leak on the 4-6th day $(10.5 \%, \mathrm{n}=2)$. Out of the IBIs, $63.2 \%(n=12)$ were on the posterior wall, $21.1 \%$ $(n=4)$ on the anterior wall and $15.7 \%(n=3)$ on the dome of the urinary bladder. Most of the IBIs were managed by the Gynaecologist $(63.2 \%, \mathrm{n}=12)$ intra-operatively and only a small proportion $(36.8 \%, \mathrm{n}=7)$ by the Urologist (Table 1). The requirement of Urologist management was more during Laparoscopy-assisted Vaginal Hysterectomies (LAVH) (15.8\%, $\mathrm{n}=3)$ followed by Total Abdominal hysterectomies (TAH) $(10.5 \%, n=2)$. But there was no significant difference in requirement of Urologist or Gynaecologist management for Obstetric and gynaecological procedures $(\mathrm{p}=0.6)$. Most of the IBIs happened during the dissection of the bladder flap $(57.9 \%, \mathrm{n}=11)$, but there was no significant difference in occurrence while operated with or without an urologist $(p=0.95)$. The requirement of urologist was more felt during posterior bladder wall injuries $(26.3 \%, \mathrm{n}=5)$ compared to other regions of the bladder but the difference was not significant $(\mathrm{p}=0.94)$. Associated left ureteric injury was encountered in only one case.

Table 1: Difference and requirement of urologist in management of IBIs.

\begin{tabular}{|c|c|c|c|}
\hline & $\begin{array}{l}\text { Urologist } \\
(n=7)\end{array}$ & $\begin{array}{l}\text { Gynaecologist } \\
(\mathrm{n}=12)\end{array}$ & $\begin{array}{l}P \\
\text { value }\end{array}$ \\
\hline \multicolumn{4}{|c|}{ Operative procedure } \\
\hline LAVH & 3 & 1 & $\begin{array}{l}0.79 \\
\mathrm{df}=3^{* *}\end{array}$ \\
\hline TAH & 2 & 3 & \\
\hline VH & 1 & 4 & $0.60 *$ \\
\hline $\operatorname{LSCS}^{1}$ & 1 & 2 & \\
\hline PS & 0 & 2 & \\
\hline \multicolumn{4}{|l|}{ Time of injury } \\
\hline $\begin{array}{l}\text { Dissection of } \\
\text { bladder flap1 }\end{array}$ & 4 & 7 & \\
\hline $\begin{array}{l}\text { Opening the } \\
\text { abdomen }\end{array}$ & 2 & 5 & \\
\hline $\begin{array}{l}\text { End of the } \\
\text { procedure }\end{array}$ & 1 & 0 & $0.95 *$ \\
\hline $\begin{array}{l}\text { Average } \\
\text { length of } \\
\text { bladder injury }\end{array}$ & $4.5 \mathrm{cms}$ & $2.8 \mathrm{cms}$ & $\begin{array}{l}0.67 * * \\
*\end{array}$ \\
\hline $\begin{array}{l}\text { Follow-up } \\
\text { cystoscopy } \\
\text { done }\end{array}$ & 3 & 1 & \\
\hline \multicolumn{4}{|l|}{ Site of IBI } \\
\hline Anterior wall & 1 & 3 & \\
\hline Posterior wall $^{1}$ & 5 & 7 & $0.94 *$ \\
\hline Dome & 1 & 2 & \\
\hline
\end{tabular}

*Fischer Exact test; 1-Reference; **Chi-square test for trends (Yates Correction); ***Mann-Whitney U test.

\section{DISCUSSION}

Iatrogenic bladder injuries (IBI) are more commonly associated with OBG procedures with frequencies ranging from 0.2 to 19.6 per 1000 surgeries commuting to 2.6 per 1000 on an average. ${ }^{1,2}$ In the present study the incidence of bladder injuries was high (13.3 per 1000) 
compared to the other studies done elsewhere considering a study period of 5 years. The occurrence of IBI was more common during Gynaecological procedures $(84.2 \%, \mathrm{n}=14)$ than during Obstetric procedures $(15.7 \%$, $\mathrm{n}=5)$. This result was contrary to the previous studies which showed occurrence of IBI more common during obstetric procedures $(61 \%$ per 1000$)$ than during gynaecological surgeries $(1.5 \%$ per 1000$) .{ }^{3-5}$ Most of the IBIs were detected and managed intraoperatively $(89.5 \%)$ similar to that $(90 \%)$ in a study by Pandyan et al. ${ }^{6}$ The same study discussed higher incidence of IBIs among $\operatorname{LSCS}(n=16,80 \%)$ and a lower incidence $(n=3,15 \%)$ among hysterectomies. In this study, the incidence of IBIs among LSCS $(n=3,15.8 \%)$ was lower compared to the incidence $(n=14,73.7 \%)$ among hysterectomies. IBIs during LSCS were mostly at the anterior wall of bladder $(66.7 \%, \mathrm{n}=2)$ and managed by the gynaecologists. IBIs during hysterectomies were mostly at the posterior wall of bladder $(85.7 \%, n=12)$ and $41.6 \%(n=5)$ of them were managed by the urologists. Harkki-Siren $\mathrm{P}$ et al reported the risk of ureteral injury is higher after laparoscopic hysterectomy compared to traditional hysterectomies. ${ }^{7}$ In this study, among the total 14 hysterectomies with IBIs only $4(28.5 \%)$ were laparoscopic assisted vaginal hysterectomies showing reduced occurrence of injuries during laparoscopic procedures. All the bladder defects were sutured in 2 layers and bladder integrity checked by distension of the bladder. In majority $(n=14,73.7 \%)$ of cases, the Foley's catheter was kept in situ for 2 to 3 weeks. Only two cases required follow-up cystoscopy at 3rd and 6th week after surgery. Both the cases had IBIs following Laparoscopic assisted vaginal hysterectomies complicated by development of Vesico-vaginal fistula and required open repair by urologist.

\section{CONCLUSION}

The occurrence of IBIs was more common during Gynaecological procedures than during obstetric procedures. Most of the gynaecological procedures especially hysterectomies require the expertise presence of an urologist. The prevention of Bladder injuries during OBG procedures can be done by taking Pre-operative investigations include ultrasonography, prophylactic ureteric catheterization in suspected cases of difficult dissection and IVP when uterus size is equal to or more than 12 weeks and adnexal masses equal to or more than
$4 \mathrm{~cm}$. Intra-operatively, adequate exposure, full examination, early urological assistance, avoiding blind clamping of blood vessels, operating close to the pathology, identification of the ureter in its course before dissection, careful mobilization from the operative site and short diathermy application can prevent IBIs.

Funding: No funding sources

Conflict of interest: None declared

Ethical approval: The study was approved by the Institutional Ethics Committee

\section{REFERENCES}

1. Gilmour DT, Dwyer PL, Carey MP. Lower urinary tract injury during gynecologic surgery and its detection by intraoperative cystoscopy. Obstet Gynecol. 1999;94:883-9

2. Peng P, Shen K, Lang J, Wu M, Haung H, Pan LI. Clinical analyses of 42 cases of urinary tract injury in gynecologic surgery. Zhonghua Fu Chan Ke Za Zhi. 2002;37:595-7.

3. Reynaldo G, Ceballos L, Coburn M, JN Corriere, MC Dixo Lobels B, et al. Consensus statement on bladder injuries. BJU Internat. 2004;94:27-32.

4. Rajasekar D, Hall M. Urinary tract injuries during obstetric intervention. $\mathrm{Br} \mathrm{J}$ Obstet Gynaecol. 1997;104:731-4.

5. Mendez LE. Iatrogenic injuries in gynecologic cancer surgery. Surg Clin North Am. 2001;81:897923.

6. Pandyan GV, Zahrani AB, Awon AR, Al-Rashid M, Al-Assiri M, Dahnoun M. Iatrogenic bladder injuries during obstetric and gynecological procedures. Saudi Med J. 2007;28(1):73-6.

7. Harkki-Siren P, Sjoberg J, Tiitinea A, Urinary tract injuries after hysterectomy. Obstet Gynecol. 1998;92(1):113-8.

Cite this article as: Sankareswari R, Ghurunaath TR, Sundharam RSS. Iatrogenic Bladder injuries during Obstetric and Gynaecological Surgeries -Does it demand prophylactic presence of an urologist? Int J Reprod Contracept Obstet Gynecol 2017;6:1570-2. 